\title{
A crise na América Latina em tempos de pandemia da Covid-19
}

No ano de 2020 o mundo se deparou com um vírus ainda desconhecido para a ciência. A pandemia se alastrava atingindo, aparentemente, da mesma forma, todos os países. Ao longo dos meses, a ciência foi buscando soluções para a trágica situação que assolava a humanidade, enquanto o COVID-19 demonstrava não ser um vírus democrático. As desigualdades se fizeram ainda mais latentes nos países pobres, os problemas se potencializaram nos locais sem infra-estrura adequada para lidar com a doença, e a crise sanitária imiscuiu-se com crises políticas, miséria, feminicídio, migrações em massa e a exclusão digital.

Os efeitos da pandemia na América Latina foram diagnosticados pela Comissão Econômica para América Latina e Caribe (CEPAL), que criou, em março de 2020, o Observatorio COVID-19 en América Latina y el Caribe. ${ }^{1}$ Os estudos cepalinos demonstraram a degradação socioeconômica da região e sugeriu políticas públicas para atenuar os efeitos do COVID-19 sobre os mais variados segmentos populacionais latino-americanos, em especial, os mais vulneráveis. Para constatar a realidade, segundo dados da Comissão, no ano de 2020, 209 milhões de latino-americanos, o que representa 1/3 da população, encontrava-se em condição de pobreza, e 78 milhões vivendo na mais extrema miséria. Além do caos sócio-econômico, a América Latina foi afetada por uma série de crises políticas que dificultaram lidar com a pandemia. Os resultados dessas crises não serão bem conhecidos até que o vírus desapareça no continente ou se estabilize como endêmico entre a população.

O dossiê "A crise na América Latina em tempos de pandemia do Covid-19” traz diferentes reflexões sobre o cenário pandêmico na região, a partir de três artigos, dois deles sobre o Brasil e um sobre a Bolívia. Entretanto, as temáticas podem romper fronteiras e se encaixar perfeitamente em muitas das realidades de distintos países latino-americanos-seguindo do México ao Chile. É importante para isso, entender o sentido de crise, a crise como a ruptura das relações e padrões de 'normalidade' do funcionamento das regras e estruturas. A construção da crise permite aos estados

\footnotetext{
${ }^{1}$ Os dados podem ser obtidos no link https://www.cepal.org/es/temas/covid-19 Acesso: 30 de novembro de 2021.
} 
exercerem um controle sobre diferentes segmentos da população, já que a crise costuma ser um prelúdio para garantir o consentimento ou apoio às medidas emergenciais tomadas pelos governos.

No entanto, nem todas as medidas adotadas pelos governos centrais receberão consentimento dos estados que constituem uma federação. É o que demonstra o texto de José Vitor Lemes Gomes, "Federalismo e Covid-19 no Brasil", que analisa quais as consequências políticas do federalismo brasileiro na autuação e relação dos entes federativos no enfrentamento da pandemia COVID-19. Segundo o autor o federalismo assegurou a autonomia dos entes subnacionais em relação à União para a adoção de medidas voltadas ao enfrentamento da pandemia, mantendo, assim, o desenho institucional do estado federal preservado. O texto, de forma esclarecedora e didática, realiza uma análise sobre o federalismo no Brasil para, na segunda parte, elucidar o conflito federativo entre o executivo federal e os governos subnacionais, que gerou inúmeros litígios e crises. Gomes demonstra as frequentes polêmicas em relação ao comportamento do presidente Bolsonaro e a ocorrência de embates entre ele e governantes de Estados e Municípios.

O segundo artigo intitulado "A educação no cenário pandêmico: o que dizem os professores da educação básica sobre o retorno às aulas presenciais", de autoria de Rosane Barreto Ramos dos Santos e Paulo Pires de Queiroz, apresenta a difícil realidade do contexto da educação em tempos de pandemia pelo novo coronavírus. Um tema necessário e que os autores analisam a partir do resultado de elaborada pesquisa qualitativa que utilizou o recurso da análise de conteúdo para o tratamento dos dados coletados nos 69 questionários aplicados aos professores da educação básica refletindo sobre o ensino remoto, a saúde mental docente e o retorno às aulas presenciais. Os resultados não são animadores, já que a educação foi um dos setores mais impactados, no Brasil, pelo advento da Covid-19. Este caso ilustra também o difícil retorno dos docentes às aulas em muitos países, debido à necessidade de preparação das instalações às condições sanitárias adequadas à nova realidade.

O terceiro e último artigo "Bolívia em tempo de pandemia: crise humanitária e conflito político", de autoria de Fabio Sousa Mendonça de Castro finaliza o dossiê trazendo o conflitivo cenário boliviano, a partir da complexa interação entre as questões sanitárias e a luta política que culminou com o regresso da esquerda ao comando do 
Estado, com a vitória de Luis Arce nas eleições de outubro de 2020. Após viver um golpe de Estado, no ano de 2019, e o exílio de Evo Morales, o país, segundo o autor, vive a falta de legitimidade dos novos governantes e sua incapacidade de conter os contágios e cuidar da população, o que provocou uma crise sanitária de grandes proporções. O texto traz uma análise sobre a Bolívia do tempo presente, suas políticas e movimentos sociais até chegar a COVID-19, que atingiu duramente o país. Durante a primeira onda da pandemia, segundo o autor, a Bolívia apresentou uma das taxas mais altas, no mundo inteiro, de contágio por milhão de habitantes, com 100 mil casos registrados em agosto de 2020, numa população de 11,6 milhão de habitantes. Duas grandes questões surgem a partir deste ensaio: É difícil saber se a pandemia exacerbou as crises políticas que a região enfrenta ou se a própria pandemia é a autora de outras crises políticas.

Lamentavelmente, as análises de cada texto demonstram que o vírus está muito longe de ser democrático e a crise sanitária torna-se, por sua vez, um poderoso instrumento para manipular e agudizar, ainda mais, as diferenças sociais ou dar impulso às crises políticas que sempre fizeram parte do cenário da América Latina. A pandemia nos ensina, de forma mortífera, que não há paz entre desiguais, e que, no caso do COVID-19, a falta de ajuda humanitária, de solidariedade quanto à distribuição das vacinas, afeta também os países ricos. Em suma, a pandemia mostra, de forma clara, as principais falhas estruturais das sociedades latino-americanas - um continente que cambaleia em direção ao futuro, sem consolidar o seu desenvolvimento e sem perder completamente a sua base.

Érica Sarmiento (Universidade do Estado do Rio de Janeiro) Tony Payan (Universidad Autónoma de Ciudad de Juarez/ Chiahuahua/ Rice University/Houston, Texas)

Dezembro 2021

DOI: 10.12957/intellectus.2021.64076 